\title{
Characterization of ceftriaxone-resistant Aeromonas spp. isolates from stool samples of both children and adults in Southern India
}

\author{
Maanasa Bhaskar, K P Dinoop and Jharna Mandal
}

\begin{abstract}
Background: Aeromonas species can cause a wide spectrum of illnesses varying from intestinal to extra intestinal and vary in their susceptibility to different antibiotics. The current study was undertaken to characterize the third generation cephalosporin-resistant strains of Aeromonas spp. which were isolated from stool specimens.

Methods: Out of a total of 2780 stool samples, 29 Aeromonas spp. were identified, out of which, 9 were resistant to ceftriaxone by the Kirby-Bauer antibiotic testing method. These strains were subjected to minimum inhibitory concentration (MIC) determination by agar dilution for ceftriaxone. Phenotypic and genotypic testing of AmpC beta-lactamase and extended spectrum beta-lactamase (ESBL) were performed. Gene transfer was carried out to demonstrate transmissibility of these genetic elements by conjugation experiments.

Results: Out of the 29 strains, 9 showed MIC of $\geq 4 \mu \mathrm{g} / \mathrm{ml}$. Seven out of 9 showed presence of blaCTX-M, while 2 more strains showed the presence of inducible AmpC beta-lactamase and presence of MOX gene. Gene transfer experiments showed that these elements were transmissible to recipient (Escherichia coli $J 53$ strain) in the presence of ceftriaxone.

Conclusions: Dissemination of these resistance determinants like plasmids is pivotal in the spread of these resistance genes into the aquatic environment into organisms like Aeromonas. This may further limit the future use of antibiotics for the treatment of diarrhoeal diseases. Hence, detection and antibiotic susceptibility testing of Aeromonas spp. should be performed when isolated from stool samples.
\end{abstract}

Keywords: Aeromonas, Diarrhoea, MIC, ESBL, AmpC beta-lactamase

\section{Background}

The family Aeromonadaceae contains the members of the genus Aeromonas which are Gram-negative rods, facultative anaerobes and oxidase-positive. They are habitants of a wide range of aquatic environment like fresh, marine and estuarine water, as well as sewage where the bacterial ecosystem co-exists as well as are natural pathogens of aquatic life forms like fishes, etc. [1].

A number of Aeromonas species are described, but the taxonomy of the genus Aeromonas is confusing because of the lack of congruity between the phenotypic and genotypic characters. Now, several DNA hybridization

\footnotetext{
*Correspondence: drjharna@gmail.com

Department of Microbiology, JPMER, Puducherry, India
}

methods are available based on which Aeromonas species are classified [1, 2]. Important Aeromonas species which are pathogenic for humans include Aeromonas hydrophila, Aeromonas sobria, Aeromonas trota, and Aeromonas caviae $[1,3,4]$.

Today, Aeromonas species are considered not only pathogenic to cold-blooded animals and fishes, some of the species are pathogenic to animals and humans also, both immunocompetent and immunocompromised. The spectrum of infections caused by Aeromonas species varies from various intestinal manifestations to extra intestinal complications namely gastrointestinal tract syndromes, wound and soft tissue infections, urinary tract infections and rarely septicaemia $[1,2]$. 
The role of Aeromonas as a gastrointestinal pathogen has been controversial as 1-4 \% of asymptomatic individuals are known to harbour them in their gut. However, Aeromonas-associated acute bacterial gastroenteritis has been reported from across the world. The gastrointestinal manifestations can vary from an acute gastroenteritis presenting with an acute watery diarrhoea, choleraic illness to a more severe form accompanied by dysentery rarely leading to hemolytic uremic syndrome [1-4].

Susceptibility to the antibiotics varies according to the geographical area and the species of Aeromonas tested. Most of the isolates are generally susceptible to tetracyclines and quinolones though development of increasing resistance to third generation cephalosporins due to the production of beta-lactamases and extended spectrum beta-lactamases (ESBLs) has been noted in the recent years $[2,3,5]$. The current study was undertaken to characterize the third generation cephalosporin-resistant strains of Aeromonas spp. which were isolated from stool specimens.

\section{Methods}

The present study was a descriptive study conducted in a tertiary care centre in South India. All consecutive non-duplicate stool isolates of Aeromonas spp. resistant/ intermediate to ceftriaxone by Kirby-Bauer disc diffusion method during a study period of 3 years from January 2010 to December 2012 were included in the study. These isolates were characterized phenotypically and genotypically for determining ceftriaxone resistance mechanisms.

\section{Bacterial isolates}

A total of 2780 stool samples were processed, out of which, 29 (1.04 \%) Aeromonas spp. were identified. Total samples positive for other pathogens were Shigella (6.1\%), non-typhoidal salmonellae (1.29 \%) and Vibrio cholerae (7\%) among the bacterial causes of diarrhoea, during the study period of 2 years using the cultural characteristics and standard biochemical reactions, followed by confirmation with respective antisera wherever applicable [6, 7]. In these 29 patients, no other pathogen was isolated, and Aeromonas spp. were the single pathogen isolated.

\section{Antimicrobial susceptibility testing}

Antimicrobial susceptibility testing of all the isolates was performed on Mueller-Hinton agar plates by standard Kirby-Bauer disc diffusion method as per the standard procedure mentioned in Clinical Laboratory Standards Institute guidelines for Aeromonas spp. [8]. The isolates were tested to the following panel of antibiotics including the beta-lactam and the non-beta lactam group of antibiotics namely ceftriaxone $(30 \mu \mathrm{g})$, ciprofloxacin $(5 \mu \mathrm{g})$, tetracycline $(30 \mu \mathrm{g})$, cotrimoxazole $(1.25 / 23.75 \mu \mathrm{g})$ and chloramphenicol $(30 \mu \mathrm{g})$. All the isolates resistant to ceftriaxone were further subjected to minimum inhibitory concentration (MIC) determination for ceftriaxone and characterized phenotypically and genotypically for other cephalosporin resistance mechanisms like AmpCBL (betalactamase) production. Since the current updated CLSI guidelines do not necessarily recommend performing ESBL testing routinely with the modified zone diameters for ceftriaxone, we therefore did not perform any further phenotypic tests for the ESBL production.

Determination of MIC-MIC of a particular strain intermediate/resistant to ceftriaxone by routine disc diffusion method was determined using ceftriaxone agar dilution method using ceftriaxone pure powder (Himedia, Mumbai, India). MIC was performed on Mueller-Hinton agar containing doubling dilutions of ceftriaxone ranging from 0.5 to $8 \mu \mathrm{g} / \mathrm{ml}$. Plates were incubated at $37{ }^{\circ} \mathrm{C}$ for $18 \mathrm{~h}$. MIC value of $\leq 1 \mu \mathrm{g} / \mathrm{ml}$ is considered to be sensitive, $2 \mu \mathrm{g} / \mathrm{ml}$ to be intermediate and $\geq 4 \mu \mathrm{g} / \mathrm{ml}$ to be resistant to ceftriaxone [6-8].

Detection and identification of various beta-lactamase genes-All the Aeromonas species resistant to ceftriaxone by disc diffusion method and further by agar dilution method was further subjected to PCR for identification of various beta-lactamases viz-ESBLs and AmpCBLs.

Preparation of template DNA-DNA was extracted from the isolates by using the boiling method as described previously [9].

ESBL gene detection-Most of the ESBLs genes are variants of blaTEM and blaSHV, but blaCTX-M are also increasingly becoming important. The various genes targeted for detection of ESBLs in the present study were blaTEM,blaSHV and blaCTX-M. A duplex PCR for blaTEM and blaSHV was done using the primer sequence and the cycling conditions of Jemima et.al. [9], and a simple PCR was performed for the detection of blaCTX$\mathrm{M}$-sing the primer sequence and the cycling conditions as mentioned previously [10]. Amplicons obtained were analyzed by gel electrophoresis using $2 \%$ agarose. Gels were stained by ethidium bromide and visualized by UV transillumination.

Detection of AmpCBL production-The various AmpCBL genes targeted were MOX, CITM, FOX, DHAM, ACCM and EBCM [11]. A multiplex PCR was performed for the detection of these genes using the primer sequence and cycling conditions as described earlier [12]. Sequencing of these genes was conducted by Macrogen Inc. (Seoul, South Korea). We used the BLASTN program (www.ncbi.nlm.nih.gov/BLAST) for database searching.

Transfer of resistance genes-A conjugation experiment for the transferability of the resistance genes was conducted using broth mating experiment with sodium azide resistant $E$. coli strain $\mathrm{J} 53$ as the recipient strain as per Lee et al. [13]. Equal volumes $(4 \mathrm{ml})$ of cultures of ceftriaxone-resistant Aeromonas strain and E. coli strain 
J53 (each at $109 \mathrm{cfu} / \mathrm{ml}$ ) grown in brain-heart infusion broth were mixed. Mixtures were incubated at $37^{\circ} \mathrm{C}$ for $18 \mathrm{~h}$. Transconjugants were selected on MacConkey agar with sodium azide $(150 \mathrm{mg} / \mathrm{l})$ to inhibit the donor strain and with ceftriaxone $(1 \mathrm{mg} / \mathrm{l})$ to inhibit the growth of the recipient strain.

Confirmation of transconjugants by PCR amplification-Three to five colonies of the transconjugants were selected to confirm the plasmid transfer of resistance genes. Colonies were picked up from the MacConkey plates containing ceftriaxone $(1 \mathrm{mg} / \mathrm{l})$ and DNA extracted from the colonies using boiling lysis method as described above. The supernatant was taken as the template for PCR amplification for detection of AmpCBL and ESBL genes.

\section{Results}

A total of 9 Aeromonas species out of 29 strains were found resistant to ceftriaxone by Kirby-Bauer disc diffusion method. All these 9 strains showed MIC of $\geq 4 \mu \mathrm{g} /$ $\mathrm{ml}$ which indicated that they were resistant to ceftriaxone. Seven out of 9 were ESBL producers and showed the presence of blaCTX-M, while 2 more strains showed the presence of inducible AmpCBL. None of these 9 isolates showed the presence of blaTEM or blaSHV. On sequencing these amplicons of blaCTX-M, we found that they had $99 \%$ identity with E. coli strain blaCTX-M-15 (Genome accession no: FJ997868.1).

Two of the 9 strains showed the presence of AmpCBL gene at 490 bp position which corresponded to the MOX gene. On sequencing, it was found to match $99 \%$ with Aeromonas punctate strain blaMOX-sequence (Genome accession no: FJ262599.1). Co-production of AmpCBL and ESBL was not found in any of our study isolates.

The results of the conjugation experiments followed by the PCR amplification of the transconjugants showed that all 9 strains (7 ESBL producers and 2 AmpCBL producers) were able to transfer their resistance genes to the E. coli $\mathrm{J} 53$ strain. These tranconjugants were subjected to PCRs for the detection of ESBL and AmpCBL genes, which confirmed the transfer in the 9 strains.

\section{Discussion}

Although the reports of ESBLs associated with Aeromonas spp. are rare when compared to the other members of Enterobacteriaceae family, the most common type of CTX-M described in India is CTX-M-15. Though there are reports on ceftriaxone resistance in Aeromonas from India, molecular characterization studies on ceftriaxone resistance from stool samples are currently not available from India. In our hospital, normally for all watery diarrhoea mainly, rehydration therapy is prescribed, and in case of invasive diarrhoea/dysentery, the antibiotic prescribed usually is cefixime. A lot of ESBLs including
TEM-24, TEM-63 and SHV-12 have also been described in Aeromonas spp. [14-17].

Previous studies unquestionably established the role (>85\% of isolates) of many Aeromonas spp. such as the A. hydrophila, A. caviae and A. veronii bv. sobria in diarrhoea $[1,5]$.

The Aeromonas have been known to carry many drug resistance genes. There are several reports citing the various mechanisms operating. These bacteria can receive and transfer antibiotic resistance genes to other Gram-negative bacteria [2].

The concern for drug resistance in these isolates is well placed as they have originated from the community, causing diarrhoea in the patients discussed. Routinely, antibiotic therapy for Aeromonas causing diarrhoea is not warranted, as it produces self-resolving diarrhoea. Hence, the finding of antibacterial resistance is of not a concern as far as diarrhoeal management goes, but since the same pathogen is associated with extra intestinal manifestations where the same resistance mechanisms, operating can spell devastation. Another point of concern is that since these genetic elements are borne on plasmids, they can be transmitted to other bacteria as well which may further limit the future use of antibiotics for the treatment of diarrhoeal diseases due to the latter bacteria. Our plasmid transfer studies have shown that these genetic elements can be easily transmitted from one bacterium to the other each belonging to different genera. This obviously raises concern knowing the fidelity and integrity of such genetic elements. The implications are far extending.

Earlier studies have reflected on the drug resistance mechanisms in this group. In a study from Kolkata, India, it was observed that many of the Aeromonas strains were resistant to furazolidone, quinolones and cephalosporins [5]. In fact, multiple drug resistance among Aeromonas spp. have been reported from many parts of the world [16, 18]. In both clinical as well as environmental isolates of Aeromonas, antibiotic resistance has been observed. In many studies, an increase in resistance was observed among strains of Aeromonas isolated from urban effluents being discharged into rivers $[17,19,20]$. It has been demonstrated in earlier studies that household and industrial effluents are known to contain high levels of antibiotics and antibiotic-resistant bacteria of human and animal origin [19-22].

Based on the findings of the PCR and the sequencing, the genes are plasmid-borne which is evident from the plasmid transfer assays. This raises further concern about such elements operating in the environment. Aeromonas species producing extended spectrum betalactamases are increasingly being reported. Infections caused by Aeromonas harbouring ESBL genes and AmpCBL genes is an important problem in developing 
countries where infections caused by Aeromonas is common. Organisms expressing AmpCBL is an important clinical concern since these isolates are usually resistant to all beta-lactam antibiotics except the fourth generation cephalosporins like cefepime, cefpirome and the carbapenems [11]. Detection of this resistance mechanism is important for surveillance, epidemiological studies and hospital infection control because most of these enzymes are plasmid-mediated, and this results in the spread of resistance genes among the members of the same as well as different families. Aeromonas spp. in water habitats act as mediators between water and commensal gut bacteria especially members of the Enterobacteriaceae, which further act as the progenitors of the most commonly encountered plasmidic-AmpC genes detected in clinical isolates. These genes have been reported from water bodies and drinking water biofilms [23-25] so much so that the presence of genetic elements with sequence homologies to those of bacterial species such as $V$. cholerae and Photobacterium damselae have also been found [26].

Like human gut, water sources act as excellent reservoirs where transfer of genetic material including antibiotic resistance genes can occur as demonstrated by earlier workers [11, 24, 26-32]. In strains of Aeromonas isolated from the several water bodies demonstrated the presence of AmpCBLs, quinolone resistance determinants and tetracycline efflux gene, which in turn indicate that the water bodies are getting polluted with antibiotics. This might be acting as a selection pressure responsible for selecting out drug-resistant strains in the environment.

The mechanisms of resistance to third generation cephalosporins in Aeromonas have been ascribed to the production of beta-lactamases (ESBLs, AmpCBLs and carbapenemases), efflux pumps and alterations in the outer membrane leading to reduced permeability, though in the present study, we did not look for any of the efflux pumps or alterations in the outer membrane.

\section{Conclusions}

Antibiotic usage in the clinical and non-clinical settings is important for the emergence of antibiotic-resistant isolates. ESBL and AmpCBL production are one of the important resistance mechanisms conferring resistance to penicillins and cephalosporins. Emergence of these resistance mechanisms in Aeromonas species is important as these organisms are one of the emerging pathogens in both immunocompetent and immunocompromised patients producing a variety of clinical manifestations. Occurrence of ESBLs and AmpCBLs in Aeromonas species emphasizes the importance of constant surveillance of clinical isolates for the prevalence of antibiotic resistance genes, though routine testing of stool isolates is not recommended. Dissemination of these resistance determinants due to its location on mobile genetic elements like plasmids plays an important role in the spread of these resistance genes in the environment which may further limit the future use of antibiotics for the treatment of diarrhoeal diseases.

\section{Competing interests}

The authors declare that they have no competing interests.

\section{Authors' contributions}

All authors read and approved the final manuscript.

Received: 3 June 2015 Accepted: 22 November 2015

Published online: 01 December 2015

\section{References}

1. Janda JM, Sharon L. The genus Aeromonas: taxonomy, pathogenicity, and infection. Clin Microbiol Rev. 2010;23:35-73.

2. Vila J, Ruiz J, Gallardo F, Vargas M, Soler L, Figueras MJ, et al. Aeromonas spp. and traveler's diarrhea: clinical features and antimicrobial resistance. Emerg Infect Dis. 2003;9:552-5.

3. Essers B, Burnens AP, Lanfranchini FM, Somaruga SGE, Von Vigier RO, Schaad UB. Acute community acquired diarrhea requiring hospital admission in Swiss children. Clin Infect Dis. 2000;30:192-6.

4. Champsaur H, Andremont A, Mathieu D, Rottman E, Auzepy P. Cholera-like illness due to Aeromonas sobria. J Infect Dis. 1982;145:248-54.

5. Mandal J, Dhodapkar R, Acharya NS, Sastry A, Parija SC. Urinary tract infection due to Aeromonas spp., a lesser known causative bacterium. J Infect Dev Ctries. 2010;4:679-81.

6. Abbott SL. Aeromonas and Plesiomonas. In: Murray PR, Baron EJ, Pfaller MA Tenover FC, Yorken RH, editors. Manual of clinical microbiology. 10th ed. Washington: American Society for Microbiology Press; 2011. p. 716-22.

7. James HJ, John DT, Murray PR, Baron EJ, Jorensen JH, Landry ML, et al. Susceptibility test methods: dilution and disk diffusion methods. In: Manual of clinical microbiology. 10th ed. Washington: American Society for Microbiology Press; 2007. p. 1152-72.

8. Clinical and Laboratory Standards Institute (CLSI). Methods for antimicrobial dilution and disk susceptibility testing of infrequently isolated or fastidious bacteria; approved guideline. M45A2. 2nd ed. Wayne: CLSI; 2010.

9. Jemima SA, Verghese S. Multiplex PCR for blaCTX-M \& blaSHV in the ESBL producing Gram-negative isolates. Indian J Med Res. 2008;128:313-7.

10. Kim S, Kim J, Kang Y, Park Y, Lee B. Occurrence of ESBL in the members of the genus Shigella in the Republic of Korea. J Clin Microbiol. 2004;42:5264-9.

11. Jacoby GA. AmpC beta-lactamases. Clin Microbiol Rev. 2009;22:161-82.

12. Pérez-Pérez FJ, Hanson ND. Detection of plasmid-mediated AmpC beta-lactamase genes in clinical isolates by using multiplex PCR. J Clin Microbiol. 2002;40:2153-62.

13. Lee SH, Kim JY, Lee GS, Cheon SH, An YJ, Jeong SH, et al. Characterization of blaCMY-11, an AmpC-type plasmid-mediated $\beta$-lactamase gene in a Korean clinical isolate of Escherichia coli. J Antimicrob Chemother. 2002;49:269-73.

14. Ramalivhana JN, Obi CL, Moyo SR. Prevalence of extended-spectrum b-lactamases producing Aeromonas hydrophila isolated from stool samples collected in the Limpopo province, South Africa. Afr J Microbiol Res. 2010;4(12):1203-8.

15. Al-Ammar MH. Detection of extended-spectrum $\beta$-lactamases in Aeromonas hydrophila isolated from stool samples in the Babylon Province Iraq. Int Res J Microbiol. 2012;3(9):317-21.

16. Marchandin H, Godreuil S, Darbas H, Jean-Pierre H, Jumas-Bilak E, Chanal C, et al. Extended-spectrum $\beta$-lactamase TEM-24 in an Aeromonas clinical strain: acquisition from the prevalent Enterobacter aerogenes clone in France. Antimicrob Agents Chemother. 2003;47:3994-5.

17. Wu CJ, Chuang YC, Lee MF, Lee CC, Lee HC, Lee NY, et al. Bacteremia due to extended-spectrum- $\beta$-lactamase-producing Aeromonas spp. at a medical center in southern Taiwan. Antimicrob Agents Chemother. 2011;55(12): 5813-8.

18. Ko CW, Yu KW, Liu CY, Huang CT, Leu SH, Churarg YC. Increasing antibiotic resistance in clinical isolates of Aeromonas strain in Taiwan. Antimicrob Agents Chemother. 1996;140:1260-2.

19. Sinha SJ, Himada T, Ramamurthy T, Bhattacharya SK, Yamasaithi S, Yakada T, et al. Prevalence serotype distribution antibiotic susceptibility and genetic 
profiles of mesophilic Aeromonas species isolated form hospitalized diarrhea cases in Kolkata. Indian J Med Microbiol. 2004:53:527-34.

20. Bhattacherjee JW, Pathak SP, Gaur A. Antibiotic resistance and metal tolerance of coliform bacteria isolated from Gomati River water at Lucknow city. J Gen Appl Microbiol. 1988;34:391-9.

21. Goñi-Urriza M, Capdepuy M, Arpin C, Raymond N, Caumette P, Quentin C. Impact of an urban effluent on antibiotic resistance of riverine Enterobacteriaceae and Aeromonas spp. Appl Environ Microbiol. 2000;66:125-32

22. Kathuria V. Controlling water pollution in developing and transition countries-lessons from three successful cases. J Environ Manage. 2006;78:405-26.

23. Bhowmik P, Bag PK, Hajra TK, De R, Sarkar P, Ramamurthy T. Pathogenic potential of Aeromonas hydrophila isolated from surface waters in Kolkata, India. J Med Microbiol. 2009;58:1549-58.

24. Kim J, Kang HY, Lee Y. The identification of CTX-M-14, TEM-52, and CMY-1 enzymes in Escherichia coli isolated from the Han River in Korea. J Microbiol. 2008:46:478-81.

25. Mataseje LF, Neumann N, Crago B, Baudry P, ZhanelGG LM, Mulvey MR. Characterization of cefoxitin resistant Escherichia coli isolates from recreational beaches and private drinking water in Canada between 2004 and 2006. Antimicrob Agents Chemother. 2009;53:3126-30.

26. SchwartzT KW, JansenB OU. Detection of antibiotic-resistant bacteria and their resistance genes in waste water, surface water, and drinking water biofilms. FEMS Microbiol Ecol. 2003;43:325-35.

27. Gordon L, Cloeckaert A, Doublet B, Schwarz S, Bouju-Albert A, Ganiere JP, et al. Complete sequence of the floR-carrying multi-resistance plasmid pAB5S9 from fresh water Aeromonas bestiarum. J Antimicrob Chemother. 2008;62:65-71.

28. Henriques IS, Fonseca F, Alves A, Saavedra MJ, Correia A. Occurrence and diversity of integrons and beta-lactamase genes among ampicillin-resistant isolates from estuarine waters. Res Microbiol. 2006;157:938-47.

29. Figueira V, Vaz-Moreira I, Silva M, Manaia CM. Diversity and antibiotic resistance of Aeromonas spp. in drinking and waste water treatment plants. Water Res. 2011:45:5599-611.

30. Cattoir V, Poirel L, Aubert C, Soussy CJ, Nordmann P. Unexpected occurrence of plasmid-mediated quinolone resistance determinants in environmental Aeromonas spp. Emerg Infect Dis. 2008;14:231-7.

31. Picao RC, Poirel L, Demarta A, Silva CS, Corvaglia AR, Petrini O, et al. Plasmid-mediated quinolone resistance in Aeromonas allosaccharophila recovered from a Swiss lake. J Antimicrob Chemother. 2008;62:948-50.

32. XiaR GX. ZhangY, Xu H. gnrVC-like gene located in a novel complex class 1 integron harbouring the ISCR1 element in an Aeromonas punctate strain from an aquatic environment in Shandong Province, China. Antimicrob Agents Chemother. 2010;54:3471-4.

\section{Submit your next manuscript to BioMed Central and we will help you at every step:}

- We accept pre-submission inquiries

- Our selector tool helps you to find the most relevant journal

- We provide round the clock customer support

- Convenient online submission

- Thorough peer review

- Inclusion in PubMed and all major indexing services

- Maximum visibility for your research 